\title{
Prevalence of Renal Colic in the Emergency Departments: A Multi-center Study
}

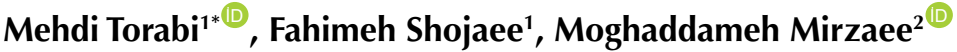 \\ ${ }^{1}$ Department of Emergency Medicine, Kerman University of Medical Sciences, Kerman, Iran \\ ${ }^{2}$ Institute for Futures Studies in Health, Kerman University of Medical Sciences, Kerman, Iran
}

*Corresponding Author: Mehdi Torabi, M.D., Associate Professor of Emergency Medicine, Department of Emergency Medicine, Kerman University of Medical Sciences, Kerman, Iran. Tel: +98-34-32235011, Fax: +98-34-32474638, Email: mtorabi1390@yahoo.com, me_torabi@kmu.ac.ir

Received December 21, 2020; Accepted June 19, 2021; Online Published August 1, 2021

\begin{abstract}
Background: Kidney calculi are the most common cause of kidney failure.

Objectives: This study aimed to investigate the prevalence of renal colic and its risk factors in the patients referred to two emergency departments during a year.

Methods: This was a descriptive cross-sectional study conducted in two hospitals in Kerman city, south-east of Iran, for one year from March 2019 to March 2020. All the archives of the two emergency departments were reviewed, and the required information was recorded in a checklist. The data was analyzed in SPSS 20 software.

Results: A total of 504 patients were included in the study. The prevalence of renal colic was $0.5 \%$. Most of the patients (58.5\%) had an age between 19 and 39 years, and the majority (60.1\%) were males and had a body mass index (BMI) above 25. A family history of renal colic was reported in $68.7 \%$ of the patients, and $63.9 \%$ had either hypertension or diabetes. Most of the patients consumed less than 3 liters of water per day. The highest referrals were seen in autumn $(31.5 \%)$ and summer $(27.4 \%)$.

Conclusion: Considering the relationship between renal colic and age, sex, BMI, occupation, a family history of the disease, the presence of underlying diseases, the amount and type of drinking water, and the season of referral, it is recommended to control these risk factors to reduce the incidence of the disease.

Keywords: Body Mass Index, Emergency Department, Kidney Calculi, Prevalence, Renal Colic
\end{abstract}

\section{Background}

Renal colic is a disease characterized by severe and sudden abdominal pain secondary to the dilatation, stretching, and spasm caused by acute ureteral obstruction. The prevalence of renal colic has been estimated as $1 \%$ to $15 \%$ during a lifetime; however, this varies based on age, sex, race, and geographical location. ${ }^{1}$ The incidence of urinary calculi is generally observed during the fourth to sixth decades of life and closely depends on environmental and genetic factors. ${ }^{2}$ Furthermore, the incidence of urinary stones can be influenced by other factors such as gender, positive family history, ${ }^{3,4}$ and the type and amount of fluids consumed. ${ }^{5}$

\section{Objectives}

Considering the close association between renal failure and kidney stones, we aimed to investigate the prevalence of renal colic and its risk factors in the patients referred to two emergency departments during one year. It is important as characterizing the risk factors of kidney stones can help reduce the prevalence of the disease in society.

\section{Methods}

\subsection{Study Design and Setting}

This study was a descriptive cross-sectional study performed on patients with renal colic, referred to two emergency departments in Kerman city, south-east of Iran, from March 2019 to March 2020.

\subsection{Participants}

The eligible candidates comprised renal colic patients aged at least 18 years. The information was collected by reviewing clinical archives and recorded in a checklist. In case of any missing data, it was collected by making phone calls.

\subsection{Variables}

Data collection tool was included a questionnaire to gather demographic information including age, sex, body mass index (BMI), occupation, a family history of kidney stones, smoking, opium use, underlying diseases, daily water consumption, the type of water consumed, a history of recurrent urinary infections, and the season of referral

Copyright $\odot 2021$ The Author(s). This is an open-access article distributed under the terms of the Creative Commons Attribution License (http:// creativecommons.org/licenses/by/4.0), which permits unrestricted use, distribution, and reproduction in any medium, provided the original work is properly cited. 
(including the Ramadan in which Muslims fast). The information was collected by reviewing clinical archives and recorded in a checklist. In case of any missing data, it was collected by making phone calls.

\subsection{Statistical Methods}

The data was analyzed using SPSS 20 software. Qualitative variables were described by frequency and percentage.

\section{Results}

Overall, 544 patients were included in the study, but 40 were excluded due to incomplete information about their demographic findings. There were 100000 visits to the University of Kerman Emergency Departments (EDs). The overall prevalence of renal colic was $0.5 \%$. The mean age of the patients was $37.84 \pm 15.14$ years, and $58.5 \%$ of them had an age between 19 to 39 years. Most of the participants were male $(60.1 \%)$, and $80 \%$ had a BMI $>25$. The majority of the patients were self-employed (35.3\%), housewives (26.2\%), and employees (25.8\%). A family history of renal colic was noted in $68.7 \%$. There was no history of smoking or opium consumption in $93 \%$ of the patients. On the other hand, hypertension and diabetes were observed in 37.5\% and $31.2 \%$ of the patients. Most of the patients $(88.9 \%)$ consumed less than 3 liters of water per day, and 76\% used tap water. No history of recurrent urinary tract infections was reported in $88.3 \%$ of the patients. The highest referrals were recorded in autumn (31.5\%), and summer $(27.4 \%)$, and the lowest was related to spring (16.1\%). The referral rate during the holy month of Ramadan was $1.4 \%$. Table 1 shows descriptive information for the variables relevant to these patients.

\section{Discussion}

Renal colic is one of the most common kidney diseases, dragging many patients to medical centers each year. Therefore, understanding the factors associated with the development of this condition can be helpful to reduce the prevalence of kidney stones. Our study showed a relationship between renal colic with age, sex, BMI, occupation, family history, underlying diseases, the amount and type of consumed water, and seasonal variations.

The age of patients in the present study was from 19 to 39 years old. However, a study in the United States in 2012 demonstrated that the disease was most common in people the age of 20 to 49 years. ${ }^{6}$ Likewise, a 6-year study in Melbourne, Australia, reported that the average age of patients was 45 years. $^{7}$

In our study, men constituted the majority of patients with renal colic. There are, however, contradictory results in other studies. For example, Croppi et al, in their study in 2012, assessed the prevalence of kidney stones in an Italian urban population and found no significant difference in the prevalence of the disease between men and women. ${ }^{8}$ On the other side, Chauhan et al reported a higher prevalence of renal colic in men than women. ${ }^{9}$ Other studies also indicate a higher prevalence of the disease in men. ${ }^{10-12}$
Table 1. Patients' Characteristics

\begin{tabular}{|c|c|c|}
\hline Variables & Number & $\%$ \\
\hline \multicolumn{3}{|l|}{ Age $(y)$} \\
\hline$\leq 18$ & 24 & 4.8 \\
\hline $19-39$ & 295 & 58.5 \\
\hline $40-59$ & 135 & 26.8 \\
\hline$\geq 60$ & 50 & 9.9 \\
\hline \multicolumn{3}{|l|}{ BMI } \\
\hline$<18.5$ & 11 & 2.2 \\
\hline $18.5-24.9$ & 90 & 17.9 \\
\hline $25-29.9$ & 214 & 42.5 \\
\hline$>30$ & 189 & 37.5 \\
\hline \multicolumn{3}{|l|}{ Occupation } \\
\hline Self-employed & 178 & 35.3 \\
\hline Housewives & 132 & 26.2 \\
\hline Employees & 130 & 25.8 \\
\hline Others & 64 & 12.7 \\
\hline \multicolumn{3}{|l|}{ Underlying disease } \\
\hline Hypertension & 189 & 37.5 \\
\hline Diabetes & 157 & 31.2 \\
\hline Hyperlipidemia & 83 & 16.5 \\
\hline Thyroid disorders & 49 & 9.8 \\
\hline Prostate hypertrophy & 28 & 5.6 \\
\hline \multicolumn{3}{|c|}{ Water consumption (Liter/day) } \\
\hline$<3$ & 448 & 88.9 \\
\hline $3-7$ & 54 & 10.7 \\
\hline $8-12$ & 2 & 0.4 \\
\hline \multicolumn{3}{|l|}{ Type of water consumed } \\
\hline Urban water & 384 & 76.2 \\
\hline Purified water & 52 & 10.3 \\
\hline Mineral water & 34 & 6.75 \\
\hline Others & 34 & 6.75 \\
\hline Referral rate in Ramadan & 7 & 1.40 \\
\hline
\end{tabular}

BMI, body mass index.

In the present study, most of the patients' BMI was > $25 \mathrm{~kg} / \mathrm{cm}^{2}$. Scales et al, in their study, asserted that the prevalence of kidney stones was higher in obese people than those with a normal weight. ${ }^{6}$ Furthermore, the association of obesity with renal colic has also been established in a study by Resorlu et al. ${ }^{10}$ These observations show that the risk of kidney stones may increase with weight gain.

It seems that inactivity can play a key role in the development of kidney stones. In terms of occupation, most of our patients were either self-employed, homemakers, or employees. Hermid Pérez et al, in their study, concluded that the occupations associated with a sedentary lifestyle might increase the risk of renal colic. ${ }^{13}$

The findings of the present study revealed a family history of renal colic in most of the patients. In a cross-sectional study in Sweden in 2017, Hemminki et al described an exaggerated risk of kidney stones in individuals with a 
positive family history. ${ }^{14}$ Also, other studies have clarified that family history is a major player in developing kidney stones. ${ }^{15,16}$

Most of our patients did not smoke or use opium. However, Orth noted that smoking was a risk factor for kidney stones. ${ }^{17}$ Also, Tamadon et al reported that smoking significantly increased the risk of kidney stone formation. ${ }^{18}$ The discrepancy between findings and recent studies may be because of the concealment of opium use and smoking by a ratio of patients due to cultural issues.

In the present study, most patients with renal colic had diabetes, hypertension, or hyperlipidemia. This study was in line with the findings of Santanapipatkul et al in 2019.15 In the study of Scales et al, the development of kidney stones was strongly associated with a history of diabetes. ${ }^{6}$ Resorlu et al also showed that hypertension plays a significant role in developing kidney stones. ${ }^{10}$

The daily consumption of water was less than 3 liters in most of our patients. However, in a 2002 study by Morton et al in the United States, it was stated that the risk of developing kidney stones was high in the people who consumed low amounts of fluids per day. So, it is recommended to use adequate fluids during the day, so that urine production reaches $2.5 \mathrm{~L} / \mathrm{d} .{ }^{19}$ Considering that a decrease in urine output is a significant risk factor for kidney stone formation and renal colic recurrence, one can prevent the development of kidney stones by increasing daily water consumption. ${ }^{20-22}$

There are various notions on the relationship between the type of drinking water and the risk of kidney stone formation. While some studies completely rejected such a relationship, ${ }^{23,24}$ others reported a relationship between the risk of kidney stones and the hardness of the water. Consuming non-hard water is preferred due to a lower urinary calcium concentration and calcium-citrate index. ${ }^{25,26}$ Other studies, however, consider a minimal role for the water hardness in the formation of kidney stones. ${ }^{27}$ Although it seems irrelevant to exaggerate the role of water quality in the development of renal stones ${ }^{28}$ it is advisable to pay attention to water minerals in addition to their hardness. For instance, it has been noted that consuming mineral water, which is rich in minerals (especially bicarbonate), can influence the formation of kidney stones. ${ }^{21}$ In the present study, most patients consumed healthy water with high hardness (281.7 ppm). ${ }^{29}$ Due to a shortage in water supplies in hot seasons, electric pumps are used to suck water out of the pipes. This problem brings sand and gravel into buildings' pipes, which are then consumed along with water, which may increase the risk of kidney stone formation.

In the present study, most patients were referred in autumn and then summer. In a study in Saudi Arabia, referrals due to renal colic were significantly higher during the warmer months of the year, including June, July, and August (i.e., summer) ${ }^{30}$ Also, in the study of Chauhan et al in 2004, the prevalence of renal colic was $16 \%$ higher in the warm than cold months of the year. ${ }^{9}$ In accordance, we also observed that the prevalence of the disease increased in the summer and the following season. This phenomenon probably reflects inadequate water consumption during summer. The findings of the incidence of renal colic during the holy month of Ramadan are contradictory. In line with our study, Yunsur Sevic et al reported no elevation in the number of renal colic patients during Ramadan. ${ }^{31}$ On the other hand, Mustafa et al, in a study on 809 patients in Bahrain, reported a higher number of referrals due to renal colic during Ramadan and its following month. ${ }^{32}$

\subsection{Limitations}

The present study has several limitations. The present research was retrospective in nature, was composed of a relatively small number of patients. Some documentation and files were incomplete. Some patients did not cooperate enough in the telephone interview.

\section{Conclusion}

Considering the relationship between renal colic and age, sex, BMI, occupation, a family history of the disease, the presence of underlying diseases, the amount and type of drinking water, and the season of referral, it is recommended to control these risk factors to reduce the incidence of the disease.

\section{Authors' Contributions}

All the authors met the standards of authorship based on the recommendations of the International Committee of Medical Journal Editors (FS 40\%, MT 40\%, MM 20\%).

\section{Conflict of Interest Disclosures}

The authors declare that they have no conflicts of interest.

\section{Ethical Approval}

The Ethics Committee approved the present study of Kerman University of Medical Sciences, Kerman, Iran, with the code of IR.KMU.REC.1399.024. Moreover, informed consent was given by all the patients before the study; all information remained confidential with the researcher.

\section{References}

1. Ramello A, Vitale C, Marangella M. Epidemiology of nephrolithiasis. J Nephrol. 2000;13 Suppl 3:S45-50.

2. Romero V, Akpinar H, Assimos DG. Kidney stones: a global picture of prevalence, incidence, and associated risk factors. Rev Urol. 2010;12(2-3):e86-96.

3. Tasian GE, Ross ME, Song L, et al. Annual incidence of nephrolithiasis among children and adults in South Carolina from 1997 to 2012. Clin J Am Soc Nephrol. 2016;11(3):488496. doi:10.2215/cjn.07610715

4. Shokeir AA. Renal colic: pathophysiology, diagnosis and treatment. Eur Urol. 2001;39(3):241-249. doi: $10.1159 / 000052446$

5. Sohgaura A, Bigoniya P. A review on epidemiology and etiology of renal stone. Am J Drug Discov Dev. 2017;7(2):5462.

6. Scales CD Jr, Smith AC, Hanley JM, Saigal CS. Prevalence of kidney stones in the United States. Eur Urol. 2012;62(1):160- 
165. doi:10.1016/j.eururo.2012.03.052

7. Pincus S, Macbean C, Taylor D. The effects of temperature, age and sex on presentations of renal colic in Melbourne, Australia.Eur JEmerg Med.2010;17(6):328-331. doi:10.1097/ MEJ.0b013e32833547b7

8. Croppi E, Ferraro PM, Taddei L, Gambaro G. Prevalence of renal stones in an Italian urban population: a general practice-based study. Urol Res. 2012;40(5):517-522. doi:10.1007/s00240-012-0477-z

9. Chauhan V, Eskin B, Allegra JR, Cochrane DG. Effect of season, age, and gender on renal colic incidence. Am J Emerg Med. 2004;22(7):560-563. doi:10.1016/j.ajem.2004.08.016

10. Resorlu M, Arslan M, Resorlu EB, et al. Comparison of individuals consuming natural spring water and tap water in terms of urinary tract stone disease. Arch Ital Urol Androl. 2014;86(3):217-218. doi:10.4081/aiua.2014.3.217

11. Farooq MU, Mustafa SH, Shah MT, Khan MJ, Iftikhar O. Dietary and fluid intake habits in nephrolithiasis patients presented to Ayub teaching hospital, Abbottabad. Int J Sci Rep. 2018;4(11):274-277. doi:10.18203/issn.2454-2156. IntJSciRep20184674

12. Behzadnia MJ, Javadzadeh HR, Saboori F. Time of admission, gender and age: challenging factors in emergency renal colic - a preliminary study. Trauma Mon. 2012;17(3):329-332. doi:10.5812/traumamon.6800

13. Hermida Pérez JA, de la Paz Pérez Palmes M, Ferrer JF, Urdangarain OO, Nuñez AB. Renal colic at emergency departments. Epidemiologic, diagnostic and etiopathogenic study. Arch Esp Urol. 2010;63(3):173-187.

14. Hemminki K, Hemminki O, Koskinen AIM, et al. Familial risks in and between stone diseases: sialolithiasis, urolithiasis and cholelithiasis in the population of Sweden. BMC Nephrol. 2018;19(1):158. doi:10.1186/s12882-018-0945-y

15. Santanapipatkul K, Jantakun W, Tanthanuch M. Urinary tract stone analysis in Loei province. Insight Urol. 2019;40(2):9-18.

16. Achila O, Araya M, Simel LL, et al. An assessment of kidney stone composition and risk factors: matched case-control study at Orotta referral hospital in Asmara, Eritrea. Int J $A d v$ Community Med. 2018;1(2):7-14.

17. Orth SR. Smoking--a renal risk factor. Nephron. 2000;86(1):12-26. doi:10.1159/000045708

18. Tamadon MR, Nassaji M, Ghorbani R. Cigarette smoking and nephrolitiasis in adult individuals. Nephrourol Mon. 2013;5(1):702-705. doi:10.5812/numonthly.5251

19. Morton AR, Iliescu EA, Wilson JW. Nephrology: 1. Investigation and treatment of recurrent kidney stones. CMAJ. 2002;166(2):213-218.

20. Borghi L, Meschi T, Schianchi T, et al. Urine volume: stone risk factor and preventive measure. Nephron. 1999;81 Suppl 1:31-37. doi:10.1159/000046296

21. Sulaiman SK, Enakshee J, Traxer O, Somani BK. Which type of water is recommended for patients with stone disease (hard or soft water, tap or bottled water): evidence from a systematic review over the last 3 decades. Curr Urol Rep. 2020;21(1):6. doi:10.1007/s11934-020-0968-3

22. Mitra P, Pal DK, Das M. Does quality of drinking water matter in kidney stone disease: a study in West Bengal, India. Investig Clin Urol. 2018;59(3):158-165. doi:10.4111/ icu.2018.59.3.158

23. Sowers MR, Jannausch M, Wood C, Pope SK, Lachance LL, Peterson B. Prevalence of renal stones in a populationbased study with dietary calcium, oxalate, and medication exposures. Am J Epidemiol. 1998;147(10):914-920. doi:10.1093/oxfordjournals.aje.a009381

24. Basiri A, Shakhssalim N, Khoshdel AR, Pakmanesh H, Radfar MH. Drinking water composition and incidence of urinary calculus: introducing a new index. Iran J Kidney Dis. 2011;5(1):15-20.

25. Bellizzi V, De Nicola L, Minutolo R, et al. Effects of water hardness on urinary risk factors for kidney stones in patients with idiopathic nephrolithiasis. Nephron. 1999;81 Suppl 1:66-70. doi:10.1159/000046301

26. Rodgers AL. Effect of mineral water containing calcium and magnesium on calcium oxalate urolithiasis risk factors. Urol Int. 1997;58(2):93-99. doi:10.1159/000282958

27. Willis S, Goldfarb DS, Thomas K, Bultitude M. Water to prevent kidney stones: tap vs bottled; soft vs hard - does it matter? BJU Int. 2019;124(6):905-906. doi:10.1111/ bju. 14871

28. Jabbar F, Asif M, Dutani H, et al. Assessment of the role of general, biochemical and family history characteristics in kidney stone formation. Saudi J Biol Sci. 2015;22(1):65-68. doi:10.1016/j.sjbs.2014.06.002

29. Moslemi MK, Saghafi H, Joorabchin SM. Evaluation of biochemical urinary stone composition and its relationship to tap water hardness in Qom province, central Iran. Int J Nephrol Renovasc Dis. 2011;4:145-148. doi:10.2147/ijnrd. s25006

30. Al-Hadramy MS. Seasonal variations of urinary stone colic in Arabia. J Pak Med Assoc. 1997;47(11):281-284.

31. Cevik Y, Corbacioglu SK, Cikrikci G, Oncul V, Emektar E. The effects of Ramadan fasting on the number of renal colic visits to the emergency department. Pak J Med Sci. 2016;32(1):18-21. doi:10.12669/pjms.321.8248

32. Mustafa MN, Al-Omran AJ, Raees AA. Frequency of renal colic during the month of Ramadan. Bahrain Med Bull. 2020;42(3):189-191. 